\title{
Core Elements of a National COVID-19 Strategy: Lessons Learned from the US National HIV/AIDS Strategy
}

\author{
David R. Holtgrave ${ }^{1} \cdot$ Ronald O. Valdiserri ${ }^{2} \cdot$ Seth C. Kalichman ${ }^{3} \cdot$ Carlos del Rio $^{4} \cdot$ Melanie Thompson $^{5}$
}

Published online: 21 September 2020

○) Springer Science+Business Media, LLC, part of Springer Nature 2020

\begin{abstract}
COVID-19 has caused devastating health consequences and social inequities globally and in the United States. Unfortunately, the US has not developed a comprehensive National COVID-19 Strategy. In this editorial, we briefly review lessons about the development, structure, implementation and evaluation of the National HIV/AIDS Strategy (NHAS) for the US, and use these lessons to inform an initial proposal for a timely, dynamic, evidence-based, participatory, comprehensive and impactful National COVID-19 Strategy. Without such a strategy, the national response to the COVID-19 pandemic will remain uneven across jurisdictions and less than optimally impactful on disease-related mortality, short- and long-term morbidity, and health and social inequities.
\end{abstract}

Keywords COVID-19 $\cdot$ HIV $\cdot$ Strategic planning $\cdot$ SARS-CoV-2 $\cdot$ Health disparities

\section{The Urgent Need for a National COVID-19 Strategy}

SARS-CoV-2, the virus that causes COVID-19 disease, will have soon resulted in the death of over 200,000 persons in the US [1] and is predicted to cause at least tens of thousands and possibly hundreds of thousands more deaths yet this year based on current trends [2]. As a result, COVID-19 is on track to be the third leading cause of death in the nation in 2020 behind only heart disease and cancer [3]. Stark racial and ethnic disparities exist in COVID-19, with Black, Latinx and Indigenous communities especially disproportionately impacted $[4,5]$. Further, lived experience with the disease teaches us that following acute infection, many persons

David R. Holtgrave

dholtgrave@albany.edu

1 School of Public Health, University at Albany, 1 University Place, Suite 100, Rensselaer, NY 12144, USA

2 Rollins School of Public Health, Emory University, Atlanta, USA

3 University of Connecticut, Mansfield, USA

4 Emory University School of Medicine and Rollins School of Public Health, Atlanta, USA

5 AIDS Research Consortium of Atlanta, Atlanta, USA experience long-term sequelae, sometimes with debilitating symptoms [6].

While SARS-CoV-2 is highly infectious with person-toperson airborne transmission being the major mechanism of transmission [7], there are highly effective, evidence-based non-pharmacologic preventive strategies that have been shown to be highly effective in areas such as New York State where numbers of cases, percent positivity, and deaths were reduced to dramatically lower levels in a few months' time [8]. The non-pharmacologic prevention toolbox includes testing, contact tracing, the wearing of face masks, physical distancing, hand washing, disinfecting of surfaces, staying home when ill, and improved air filtration strategies, among others $[9,10]$. Further, while there is currently no vaccine or cure for COVID-19, case fatality rates have declined due to improved clinical treatment strategies and the availability of partially effective medicines [11]. Trust in science and public health, however, has suffered from heavy politicization that has compromised prevention efforts and threatens to diminish uptake of upcoming vaccines and treatments.

Even prevention strategies with evidence-based efficacy are not yet being delivered at sufficient scale, or to regions and populations with greatest need. Witness, for instance, the opening of businesses in some states, such as Florida, while those jurisdictions had very high levels of community transmission with relatively few precautionary measures in place [12]. Given this reality of uneven response to the 
pandemic across the US [13], there have been many calls in the media and literature for a truly comprehensive National COVID-19 Strategy (NC19S) to be put into place in the US [14]. While there are elements of guidance about COVID-19 prevention and treatment available (e.g., CDC prevention guidance documents [15], NIH treatment guidelines [11], and White House Coronavirus Task Force reports [16]), there is no integrated document that puts into one place a coordinated national approach to fully address COVID-19. In particular, there is no NC19S that comprehensively lays out in one document the epidemiology of the challenge at hand; the evidence-base for interventions and policies to address the epidemic (i.e., in terms of preventing infections, minimizing morbidity, and addressing the substantial social disparities and disruptions that have been wrought by the pandemic); metrics and goals by which to measure progress; and processes for transparency, broad stakeholder participation, and continuous recalibration. The extant proposal in the literature that is the closest to such a plan is the call by Hotez [17] for the US to achieve one COVID-19 case per million residents per day (or other selected benchmark) by October 1, 2020, and that each State in the US would be required to achieve that key benchmark as well by the same date.

Clearly a comprehensive NC19S is urgently needed; at the current rate of approximately 1000 deaths per day from COVID-19, 41 Americans continue to die every hour of COVID-19 (as of the writing of this paper). Here, we propose the elements of such an NC19S, and to do so we draw on our experiences with the National HIV/AIDS Strategy (NHAS) of July 2010 [18], and its update in 2015 [19]. Indeed, the NHAS provides clear, useful guidance as to the structure and elements of a potential NC19S.

\section{National HIV/AIDS Strategy Structure}

The NHAS was launched in July 2010 by President Obama's administration. While various elements of such a strategy were offered by multiple public and private-sector entities over the decades, the Obama Administration was the first to decide to issue and to produce one truly comprehensive strategy at the federal level of government [18]. This strategy was updated in 2015 to run through 2020 [19]. Both documents were the result of an inclusive and highly participatory, evidence-based process, and both centered around a defining vision statement: "The United States will become a place where new HIV infections are rare, and when they do occur, every person, regardless of age, gender, race/ethnicity, sexual orientation, gender identity, or socio-economic circumstance, will have unfettered access to high quality, lifeextending care, free from stigma and discrimination." [18]

The updated NHAS sought to achieve this important vision through four major overarching goals [19]: (a) reducing
HIV incidence; (b) increasing access to care and improving health outcomes for persons living with HIV; (c) reducing HIV-related and health inequities; and, (d) executing a more coordinated multi-level response to the HIV epidemic. Each overarching goal was supported by multiple, specific, evidence-based actions that needed to be taken to achieve that goal. Importantly, a set of ten measurable indicators was developed so that progress on each overarching goal could be assessed annually through the year 2020. Some of these ten indicators were focused on disease outcomes (e.g., among persons living with diagnosed HIV infection, to reduce the death rate at least 33 percent), some focused on health disparities (e.g., to reduce the diagnosis rate among young Black gay and bisexual men by at least 15 percent), and some process oriented (e.g., elevating to 90 percent the fraction of diagnosed persons living with HIV who are sustained in ongoing medical care). Further, the NHAS called for increased coordination of HIV programs across the Federal government and between Federal agencies and State, territorial, Tribal and local governments, but none of the ten quantitative indictors were focused on this particular point regarding coordination. At least for a time, reports on annual progress were made publicly available, and were used as guidance for mid-course corrections in federal programs. The NHAS, implementation plans, indicators and progress reports are available in archive form at the website HIV.gov [19].

Of particular relevance for application to COVID-19 is the NHAS scope and comprehensiveness. First, based on input from multiple sectors and audiences-including people living with HIV and persons at risk of acquisition-a well-crafted vision statement was provided as a North Star by which to guide all strategy elements. Second, major goals were defined so as to address disease prevention, treatment and disparities. Third, specific strategies were outlined for each major goal so that program and policy emphases could be identified, and where possible, the scale of the needed intervention was identified. Fourth, a set of measurable indicators was developed and an assertive goal established for each (namely in five-year terms but measurable annually). Fifth, these goals were measured and reported upon annually (at least for some time) so as to inform mid-course corrections. Sixth, all aspects of plan development, implementation and measurement were done in as transparent, inclusive and participatory way as possible. Below, we take this inspiration from the NHAS and structure the major elements of an NC19S.

\section{Proposal for National COVID-19 Strategy Structure}

The vision statement for the NHAS [18] provides a potentially useful guide for a COVID-19 vision statement and in fact, we submit, could be meaningfully utilized with only 
minimal modifications: Because of well-funded, sciencebased and accessible prevention services and strategies, "the United States will become a place where new SARS-CoV-2 infections are rare, and when they do occur, every person, regardless of age, gender, race/ethnicity, sexual orientation, gender identity, or socio-economic circumstance, will have unfettered access to high quality, life-extending care, free from stigma and discrimination".

Next, an NC19S should comprehensively address SARSCoV-2 prevention, COVID-19 treatment and the building of health equity. As one illustration of how this plan might manifest itself, we offer below an illustrative draft table of contents for the chapters of an NC19S (Table 1).

Chapters Three through Nine should specify strategies to address the particular challenge at hand, and lead to the development of measurable indicators and assertive goals. For example, in Chapter 7, one strategy might be to ensure that all persons hospitalized for treatment of COVID-19 have access to all treatments recommended in the NIH COVID19 treatment guidelines. The assertive goal might take the following illustrative form: "By March 1, 2021, 95\% of all patients hospitalized for COVID-19 will have an indication in their medical record that the NIH Treatment Guidelines therapies recommended for their course of illness were administered in a timely manner and with no disparities as to receipt of drugs." This chapter might also have the disease outcome goal of this illustrative form: "By June 1, 2021, the in-hospital fatality rate for all patients admitted with a COVID-19 diagnoses will be less than $1 \%$ with no disparities present by patient race, ethnicity, gender identity, sexual orientation, or age, nor by hospital characteristics such as urban vs rural location)." These indicators are meant to be examples as related to their form; the detailed development of a full set of indicators should be a participatory process and requires far more development and space than available in this exhortation editorial for an NC19S.

\section{Priority Next Steps}

Experience with the HIV epidemic can offer important lessons to inform the COVID-19 response [18-22]. While the 2010 NHAS and its 2015 update were led by President Obama's administration, they included many voices beyond government, including input from the Presidential Advisory Council on HIV/AIDS, community partners, health departments, community-based service providers, researchers, health care professionals, and persons living with HIV. Once

Table 1 Proposed table of contents for National COVID-19 strategy in the US

Chapter 1 Mourning the Loss: A Look Back at the Intertwined Global and National Emergence and Impact of SARS-CoV-2

Chapter 2 A Systematic Framework for a Forward Looking National COVID-19 Strategy: Using the COVID-19 Outcome Continuum and Lessons from Other Infectious Disease Pandemics

Chapter 3 Addressing with Short- and Long-Term Structural Interventions the Social Factors that Lead to Disparities in Exposure to SARSCoV-2 (including but not limited to differences in employment in essential services job categories, and housing instability and density)

Chapter 4 Preventing Transmission with Current Non-pharmacologic Mitigation Tools: Effective Interventions to Change Behavior (e.g., promoting hand washing, physical distancing and consistent mask use) and Modify the Environment to Decrease Risk of Transmission (including ensuring access to adequate personal protective equipment for healthcare providers and other workers whose jobs place them at high risk for virus acquisition)

Chapter 5 Preventing Transmission with Additional, Biomedical Prevention Tools: Developing, Utilizing and Promoting Safe and Effective Vaccines, Monoclonal Antibodies, and Other Prophylactic Interventions

Chapter 6 Ensuring Widespread Access to Early Diagnosis and Prompt Tracing and Notification of Contacts (including providing the social supports necessary to enable quarantine and isolation)

Chapter 7 Optimizing Treatment for Acute Infection and Monitoring and Addressing Long Term Consequences (including ensuring that treatment is evidence-based and follows NIH treatment guidelines [11])

Chapter 8 Racial and Ethnic Disparities in COVID-19: Building Systems to Promote Health Equity (including but not limited to addressing economic instability, employment inequity, educational opportunity inequalities, and systemic racism in health, housing, transportation, and social services $\}$

Chapter 9 Promoting Mental Health, Preventing and Treating Substance Use, and Addressing Stigma in a Pandemic Era

Chapter 10 Rebuilding an Under-resourced and Out-dated Public Health Infrastructure

Chapter 11 Measurable Metrics, Aggressive Goals, Resource Needs, Transparency in All Phases of the Process, and Mid-course Corrections

Chapter 12 Individual, Organizational, Community, and Governmental Contributions to Goal Attainment (including standardized and sciencebased steps that schools, businesses and faith communities can take to minimize viral transmission)

Chapter 13 Case Studies from Cities, Rural Areas, States, Indigenous Nations, and Global Partners: Stories of Challenge and Relative Success

Chapter 14 A Modernized Communication Strategy for Infectious Disease Outbreaks in the US and Abroad

Chapter 15 Evidence-based References 
the decision was made to craft and implement a national HIV strategy, the development of the NHAS occurred efficiently and rapidly because literally lives were (and still are) at stake. For COVID-19, the timeline for initial publication of what should be a living document could be compressed to days and weeks instead of a few months as was the case with the NHAS. Indeed, urgency and brevity may well have the benefit of forcing relative prioritization of the most important strategies. Further, given that the current Administration has opted not to develop a comprehensive National COVID19 Strategy, this effort will need to be championed and supported over time by a broad coalition in the public and private sector, perhaps by an entity that serves to affiliate and synergize the work of health department entities across the country, by a foundation with strong interests in applied public health, or under the auspices of the National Academy of Medicine. Whomever the champion may be, we believe that the initial NC19S must be drafted in the next 30 days and a final product available in 60 days (including time for public commentary on the draft). The NC19S must include mechanisms for oversight, transparency and ongoing updates. In some ways this seems like a very fast timeline given the novelty, complexity and seriousness of the endeavor, but in the COVID-19 pandemic even short time frames involve devastating health and societal consequences and there is indeed no more time to waste. Just as with HIV, lives are literally at stake and with dozens of COVID-19 deaths per hour in the US, time is most certainly of the essence.

\section{References}

1. Johns Hopkins University Coronavirus Resource Center. COVID19 Dashboard. https://coronavirus.jhu.edu/map.html. Accessed 12 Sept 2020

2. University of Washington Institute for Health Metrics and Evaluation. COVID-19 projections. https://covid19.healthdata.org/unite d-states-of-america?view $=$ total-deaths $\&$ tab $=$ trend. Accessed 12 Sept 2020

3. Centers for Disease Control and Prevention, National Center for Health Statistics. Leading Causes of Death. https://www.cdc.gov/ nchs/fastats/leading-causes-of-death.htm. Accessed 12 Sept 2020

4. Holtgrave DR, Barranco MA, Tesoriero JM, Blog DS, Rosenberg ES. Assessing racial and ethnic disparities using a COVID19 outcomes continuum for New York State. Ann Epidemiol. 2020;48:9-14.

5. Conger K, Gebeloff R, Oppel RA Jr. Native Americans feel devastated by the virus yet overlooked in the data. New York Times. 2020 Jul 31. https://www.nytimes.com/2020/07/30/us/nativ e-americans-coronavirus-data.html. Accessed 12 Sept 2020

6. Yong E. Long-haulers are redefining COVID-19. The Atlantic. 2020 Aug 19. https://www.theatlantic.com/health/archi ve/2020/08/long-haulers-covid-19-recognition-support-group s-symptoms/615382/. Accessed 12 Sept 2020

7. Lewis D. Mounting evidence suggests coronavirus is airbornebut health advice has not caught up. Nature (News Feature). 2020
Jul 8. https://www.nature.com/articles/d41586-020-02058-1. Accessed 12 Sept 2020

8. Dzhanova Y. Fauci holds up New York as model for fighting coronavirus-They did it correctly'. CNBC. $2020 \mathrm{Jul} 20$. https://www. cnbc.com/2020/07/18/fauci-holds-up-new-york-as-model-for-fight ing-coronavirus-they-did-it-correctly.html. Accessed 12 Sept 2020

9. Paltiel AD, Zheng A, Walensky RP. Assessment of SARSCoV-2 screening strategies to permit the safe reopening of college campuses in the United States. JAMA Netw Open. 2020;3(7):e2016818.

10. Flaxman S, Mishra S, Gandy A, et al. Estimating the effects of non-pharmaceutical interventions on COVID-19 in Europe. Nature. 2020;584:257-61.

11. National Institutes of Health. Coronavirus Disease 2019 (COVID19) Treatment Guidelines. 2020 Sept 1. https://www.covid19tre atmentguidelines.nih.gov/. Accessed 12 Sept 2020

12. Sarkissian A. Florida to reopen bars, pack restaurants after DeSantis claims COVID-19 under control. Politico. 2020 Sep 10. https ://www.politico.com/states/florida/story/2020/09/10/desantiswill-let-florida-restaurants-pack-dining-rooms-soon-1316481. Accessed 12 Sept 2020

13. Kaiser Family Foundation. COVID-19: Metrics by State. 2020 Sep 11. https://www.kff.org/coronavirus-covid-19/issue-brief/ state-data-and-policy-actions-to-address-coronavirus/. Accessed 12 Sept 2020

14. Lee J. A Word from the Experts: To defeat COVID-19, 'we need a unified national strategy,' says public health expert Dr. Howard Koh. MarketWatch. 2020 Sep 8. https://www.marketwatch.com/ story/to-defeat-covid-19-we-need-a-unified-national-strategysays-public-health-expert-dr-howard-koh-2020-09-03. Accessed 12 Sept 2020

15. Centers for Disease Control and Prevention. Coronavirus Disease 2019. https://www.cdc.gov/coronavirus/2019-ncov/index.html. Accessed 12 Sept 2020

16. House Select Subcommittee on the Coronavirus Crisis. Select Subcommittee releases eight week of Coronavirus Task Force reports kept secret by the White House. 2020 Aug 31. https:// coronavirus.house.gov/news/press-releases/select-subcommitt ee-releases-eight-weeks-coronavirus-task-force-reports-kept. Accessed 12 Sept 2020

17. Hotez P. Covid19 in America: An October Plan. Microbes and Infection. 2020; in press. https://www.journals.elsevier.com/micro bes-and-infection/the-novel-coronavirus-sars-cov-2/covid19-inamerica-an-october-plan. Accessed 12 Sept 2020

18. White House. National HIV/AIDS Strategy for the United States. $2010 \mathrm{Jul}$ 13. https://obamawhitehouse.archives.gov/sites/default/ files/uploads/NHAS.pdf. Accessed 12 Sept 2020

19. White House. National HIV/AIDS Strategy: Updated to 2020. 2015 Jul 30. https://www.hiv.gov/federal-response/national-hivaids-strategy/nhas-update. Accessed 12 Sept 2020

20. Valdiserri RO, Holtgrave DR, Kalichman SC. Barrier methods for the prevention of infectious diseases: decades of condom research can inform the promotion of face mask use. AIDS Behav. 2020. https://doi.org/10.1007/s10461-020-03006-w.

21. Valdiserri RO, Holtgrave DR. Responding to pandemics: what we've learned from HIV/AIDS. AIDS Behav. 2020;24(7):1980-2.

22. Valdiserri RO, West, GR, Holtgrave DR. COVID-19 testing: Lessons from the HIV testing experience. Health Affairs Blog. 2020 May 13. https://doi.org/10.1377/hblog20200511.235991/abs_. Accessed 12 Sept 2020

Publisher's Note Springer Nature remains neutral with regard to jurisdictional claims in published maps and institutional affiliations. 